\title{
The cell wall of the oleaginous yeast Trichosporon cutaneum
}

\author{
Jonathan Depree, George W. Emerson and Patrick A. Sullivan* \\ Department of Biochemistry, University of Otago, PO Box 56, Dunedin, New Zealand
}

(Received 23 December 1992; revised 22 March 1993; accepted 13 April 1993)

\begin{abstract}
The cell wall of Trichosporon cutaneum consists of $11 \%$ protein, $63 \%$ neutral carbohydrate, $9 \%$ glucosamine and $13 \%$ glucuronic acid. The sugars include glucose $(32 \%)$, mannose $(6 \%)$ and traces of xylose and galactose. The cell wall was fractionated with alkali to yield a mixture of alkali-soluble matrix components, and an alkaliinsoluble glucan associated with chitin. The alkali-insoluble glucan contained a mixture of (1-3) and (1-6) glycosidic linkages. It was only partly susceptible to digestion by the $\beta(1-3)$ glucanase, Zymolyase. The alkalisoluble fraction contained glucan, mannan and acidic polymers. The glucan was (1-3)-linked with no (1-6) linkages and only trace amounts of (1-3-6)-linked glucose. It was resistant to digestion by Zymolyase. Extensive hydrolysis of this fraction with trifluoroacetic acid released a high-molecular-mass glucuronan which had ${ }^{1} \mathrm{H}-$ and ${ }^{13} \mathrm{C}-\mathrm{NMR}$ profiles matching those of the $\beta(1-4)$ glucuronan, mucoric acid. Xylomannan was purified from isolated cell walls and from whole cells. It contained glucose, mannose, xylose, and D-glucuronic acid. It was very similar in composition and structure to the capsular polysaccharides of Cryptococcus neoformans, and to an extracellular polysaccharide produced by another yeast described as $T$. cutaneum. Electron microscopy showed that the cell wall of $T$. cutaneum has a lamellar structure characteristic of a basidiomycetous yeast rather than the electron-dense 'fuzzy coat' seen in Candida albicans.
\end{abstract}

\section{Introduction}

The organism here referred to as Trichosporon cutaneum was first isolated from the floor drain of a dairy factory and classified as Candida curvata D (Moon et al., 1978). It converts carbohydrate to edible oil with high efficiency (Boulton \& Ratledge, 1981) and unlike most yeasts (Barnett, 1981), it utilizes lactose as a carbon source. The initial step of lactose utilization by $T$. cutaneum has been studied by West et al. (1990).

von Arx \& Weijman (1979) reclassified the basidiomycetous species of Candida as Apiotrichum or Rhodotorula, based on the presence or absence, respectively, of xylose in the cell wall. In this way the organism that had been identified as Candida curvata D was reclassified as Apiotrichum curvatum ATCC 20509. Subsequently it was examined at The National Collection Of Yeast Cultures, Norwich UK (J. Davies, personal communication). Welldeveloped pseudomycelium, limited true mycelium and arthrospores were produced in plate cultures and the biochemical features of the isolate agreed with the standard description of $T$. cutaneum (Kreger-van Rij, 1984). True mycelium and arthrospores are characteristic

*Author for correspondence. Tel. 6434797863 ; fax 6434797866 . of the genus Trichosporon but not of the genus Candida, which means that the initial classification of the organism as Candida curvata D and its reclassification as Apiotrichum were invalid. The reclassification of this organism as $T$. cutaneum presents a problem however, in that a diverse mix of organisms have been given this name. One strain of $T$. cutaneum, isolated from raw sewage, produces an extracellular pentosyl mannan (Gorin \& Spencer, 1967), another strain isolated from soil is able to use phenol as a substrate (Spånning \& Neujahr, 1990). Some papers refer to an organism described as Trichosporon beigelii $[=T$. cutaneum (Guého et al., 1987; Kreger-van Rij, 1984)] which has been shown to cause systemic infections in humans (Matthews et al., 1986). Bearing all this in mind, the organism Apiotrichum curvatum ATCC 20509 will be referred to in this study as $T$. cutaneum.

Although the biochemistry of oil production and the mechanism by which this organism utilizes lactose have been studied in detail, little is known of the basic biology of $T$. cutaneum. This study of the cell wall composition and structure was undertaken both to extend the understanding of the biology and classification of this organism, and to provide basic information to aid in the design of protocols for oil extraction on an industrial scale. 


\section{Methods}

Cultures and growth conditions. Trichosporon cutaneum (Apiotrichum curvatum ATCC 20509) was obtained from Industrial Processing Division, DSIR, Wellington, New Zealand, and maintained as slope cultures on malt extract agar (Difco) at $4{ }^{\circ} \mathrm{C}$.

Cultures were grown on YPD medium $(1 \%(\mathrm{w} / \mathrm{v})$ yeast extract, $2 \%$ $(\mathrm{w} / \mathrm{v})$ peptone, $2 \%(\mathrm{w} / \mathrm{v})$ glucose) at $28^{\circ} \mathrm{C}$ as 10 litre cultures in a New Brunswick model SF-116 fermenter; agitation 400 r.p.m., aeration 10 ] $\mathrm{min}^{-1}$, with 1-2 $\mathrm{ml}$ antifoam compound A (Sigma). These cultures were inoculated with $500 \mathrm{ml}$ of a YPD culture which had been grown on a shaker for $16 \mathrm{~h}$ at $28^{\circ} \mathrm{C}$.

Analytical methods. Total neutral carbohydrate was measured using the phenol sulphuric assay (Dubois et al., 1956), with a glucose standard unless otherwise noted. The colour response per $\mathrm{mg}$ glucuronic acid and mannose at $488 \mathrm{~nm}$ was $42 \%$ and $142 \%$, respectively, of the response of glucose. All assays of neutral carbohydrate have been corrected for the presence of uronic acid where appropriate. Protein was assayed by a modified Lowry assay (Miller \& Hoskins, 1981), using the reagents described by Eggstein \& Kreutz (1967) and BSA as a standard. Amino sugar was released by hydrolysis for $18 \mathrm{~h}$ in $6 \mathrm{M}-\mathrm{HCl}$ at $110^{\circ} \mathrm{C}$ under vacuum, and measured by a modification of the Morgan-Elson assay (Ghosh \& Roseman, 1962). Using this method, it was possible to account for $85 \%$ of the dry wt of crab-shell chitin (purified according to Jeuniaux, 1966) as glucosamine Reducing sugar was measured by reaction with $p$-hydroxybenzoic acid hydrazide (Lever, 1973). Uronic acid was measured using the carbazole reaction (Bitter \& Muir, 1962) with a standard of glucuronic acid. To correct for interference by neutral sugars, control samples were treated as specified by Bitter \& Muir (1962) except that they were heated with ethanol instead of carbazole in ethanol. Uronic acids were converted to the corresponding neutral sugars by reduction with 1-ethyl-3-(3dimethyl-aminopropyl)-carbodiimide $\mathrm{HCl}$ and sodium borohydride as specified by Redgewell et al., (1988) except that denaturation of the polysaccharide with urea was not required. Glucose was measured by the glucose oxidase assay (Lloyd \& Whelan, 1969). The cell dry wt was measured by pipetting $1 \mathrm{ml}$ samples of $1: 1$ wet $\mathrm{wt} / \mathrm{vol}$. cell suspension into tared $5 \mathrm{ml}$ borosilicate tubes, drying overnight at $100^{\circ} \mathrm{C}$ and allowing them to cool in a desiccator.

All assays were performed in triplicate unless otherwise noted.

Preparation of cell walls. YPD cultures $(10 \mathrm{l})$ grown for $70 \mathrm{~h}$ yielded $800 \mathrm{~g}$ wet wt cells (dry wt $110 \mathrm{~g}$ ). The washed cells, suspended in water (1:1 wet wt/vol.) were broken in a Manton Gaulin homogenizer [6-7 passes at 12000 p.s.i. ( $83 \mathrm{MPa}$ )] or in a French Press (Aminco Maryland; two to three passes at 20000 p.s.i.). Breakage assessed by light microscopy was $>95 \%$ for the Manton Gaulin and $>98 \%$ for the French Press. The cell-wall fraction recovered by centrifuging at $16000 \mathrm{~g}$ was washed successively in $0.9 \% \mathrm{NaCl}$ (four times), water (four times), ethanol (twice), chloroform/methanol $(1: 1, v / v)$ (twice), ethanol (twice), and again in $0.9 \% \mathrm{NaCl}$ and water as above. The final yield, $12 \mathrm{~g}$ dry wt, represented $10-12 \%$ of the cell dry wt.

Alkali extraction of dry cell walls. Samples of dry cell wall $(1 \mathrm{~g})$ were extracted in $250 \mathrm{ml} 3 \%(\mathrm{w} / \mathrm{v}) \mathrm{NaOH}$ at $4{ }^{\circ} \mathrm{C}$ for $6 \mathrm{~d}$ with stirring (Fleet, 1985). The insoluble fraction was recovered by centrifuging $(27000 \mathrm{~g}$ for $30 \mathrm{~min}$ ) and was washed once with fresh alkali.

The combined supernatant and washings were adjusted to $\mathrm{pH} 6.4$ with $6 \mathrm{M}$-acetic acid and allowed to stand at $4{ }^{\circ} \mathrm{C}$ but no precipitate formed after $16 \mathrm{~h}$. Ethanol (4 vols) was then added, the precipitate was collected, washed with ethanol and dried in vacuo over $\mathrm{P}_{2} \mathrm{O}_{5}$.

The pellet from the original alkali extraction was resuspended in $100 \mathrm{ml}$ water, adjusted to $\mathrm{pH} 6.0$ with acetic acid and centrifuged. No carbohydrate was detected in the supernatant by the phenol sulphuric assay. The pellet was washed four to five times with ethanol and dried in vacuo over $\mathrm{P}_{2} \mathrm{O}_{5}$ as above.
Gas-liquid chromatography. Samples (5-10 $\mathrm{mg}$ ) were hydrolysed at $100^{\circ} \mathrm{C}$ for $2 \mathrm{~h}$ in $2 \mathrm{M}$-trifluoroacetic acid with erythritol $(0 \cdot 5-1 \mathrm{mg})$ as an internal standard. Trifluoroacetic acid was removed by drying the samples repeatedly in vacuo. Alditol acetates were prepared according to Blakeney et al. (1983) and stored in $1 \mathrm{ml}$ dichloromethane. Typically 1-5 $\mu \mathrm{l}$ samples were analysed in a Hewlett Packard 5890A gas chromatograph fitted with a BP.X70 column and flame ionization detector (Sawardeker et al., 1965). The column head pressure was 3 p.s.i., flow of hydrogen was $1 \mathrm{ml}$ per $3 \mathrm{~s}$. The column was held at an initial temperature of $180^{\circ} \mathrm{C}$ for $5 \mathrm{~min}$, then the temperature was increased at a rate of $3{ }^{\circ} \mathrm{C} \mathrm{min}^{-1}$ to a final temperature of $230^{\circ} \mathrm{C}$ and maintained for $10 \mathrm{~min}$. The injection temperature was $240^{\circ} \mathrm{C}$, the detector temperature was $280^{\circ} \mathrm{C}$. Sugars were identified by comparison of the retention times with those of standards and relative amounts were calculated using a Shimadzu C-R3A Chromatopac recorder with integrator. The limit of detection was approximately $0.2 \mu \mathrm{g}$.

Methylation. Sodium dimsyl was prepared according to the method of Sanford \& Conrad (1966). Samples (20 mg) were weighed into dry scintillation vials capped with serum stoppers, flushed with dry $\mathrm{N}_{2}$ for $\mathrm{l} \mathrm{h}$ and dissolved in dry DMSO $(4 \mathrm{ml})$ by heating at $40-70^{\circ} \mathrm{C}$ in an oil bath with stirring. The samples were reacted overnight with $1.5 \mathrm{ml}$ sodium dimsyl and methylated with $1.5 \mathrm{ml}$ methyl iodide as specified by Stoffel \& Hanflan (1973). They were then freeze-dried, extracted into chloroform and dried in vacuo. Samples were checked for active dimsyl by reaction with triphenylmethane before addition of methyl iodide (Rauvala, 1979). Each sample was methylated three times. The alkaliinsoluble fraction was dispersed in DMSO by sonication (5-6 $30 \mathrm{~min}$ cycles) and approximately $20 \%$ of the starting material became soluble in DMSO after one cycle of methylation. The remainder was discarded.

Each methylated polysaccharide was dissolved in $0.125 \mathrm{ml} 13 \mathrm{M}$ $\mathrm{H}_{2} \mathrm{SO}_{4}$ at room temperature for $45 \mathrm{~min}, 1.35 \mathrm{ml}$ of water was added and samples were hydrolysed at $110^{\circ} \mathrm{C}$ for $5 \mathrm{~h}$. Hydrolysates were neutralized with solid $\mathrm{BaCO}_{3}$, and the insoluble $\mathrm{BaSO}_{4}$ removed by centrifugation. Methylated alditol acetates were prepared as follows (J. Tamate, personal communication): the solution containing methyl sugars was concentrated to a minimal volume (approx. $0-1 \mathrm{ml}$ ) on a rotary evaporator (water bath temperature $\leqslant 30^{\circ} \mathrm{C}$ ), made up to a total of $1 \mathrm{ml}$ with $2 \%(\mathrm{w} / \mathrm{v})$ sodium borohydride and allowed to stand overnight. The excess borohydride was decomposed with glacial acetic acid and the solution was concentrated to a minimal volume as above. The residue was taken up in $2 \mathrm{ml}$ methanol and dried under nitrogen four times. The methylated sugars were dissolved in $1 \mathrm{ml}$ dichloromethane and the amorphous precipitate of sodium acetate was discarded. 1-Methyl-imidazole $(0.1 \mathrm{ml})$ and acetic anhydride $(0.2 \mathrm{ml})$ were added and samples were heated at $50-60^{\circ} \mathrm{C}$ in a water bath for $30 \mathrm{~min}$. Finally the methylated derivatives in dichloromethane were washed twice with $2 \mathrm{ml}$ water, dried with anhydrous $\mathrm{Na}_{2} \mathrm{SO}_{4}$ and stored at $-20^{\circ} \mathrm{C}$ in Teflon-capped vials.

Methylated alditol acetates were separated using a Hewlett Packard $5890 \mathrm{~A}$ gas chromatograph fitted with a BP- 1 column. Conditions were: column head pressure 10 p.s.i. $(69 \mathrm{kPa}$ ), flow of hydrogen $1 \mathrm{ml}$ per $3 \mathrm{~s}$. The temperature was held at $100^{\circ} \mathrm{C}$, for $5 \mathrm{~min}$ after injection of sample, then increased by $4{ }^{\circ} \mathrm{C} \mathrm{min}^{-1}$ to $230^{\circ} \mathrm{C}$ which was maintained for $10 \mathrm{~min}$. The injection temperature was $230^{\circ} \mathrm{C}$, detector temperature $280^{\circ} \mathrm{C}$. Samples for mass spectroscopy were assayed on a Perkin Elmer $8420 \mathrm{GC}$ fitted with a $12 \mathrm{~m}$ DB-1 column and connected to a Perkin Elmer ITD Bench top Mass Spectrometer; conditions as for the BP-1 column. Peaks were identified by comparison of fragmentation patterns with those reported by Jansson et al. (1976).

Digestion of fractions with enzymes. Isolated walls or wall fractions (10 mg) were suspended in $2 \mathrm{ml} 10 \mathrm{~mm}$-sodium citrate buffer (pH as below) and autoclaved at $120^{\circ} \mathrm{C}$ for $20 \mathrm{~min}$ to prevent bacterial growth. The samples were then incubated at $30^{\circ} \mathrm{C}$ with $1 \mathrm{mg}$ Novozyme 234 (pH 5.8) or Zymolyase $20 \mathrm{~T}$ (pH 6.5) for $48 \mathrm{~h}$. Control samples of 
wall or fractions thereof were incubated in buffer containing no enzyme. Reducing sugar was assayed by the method of Lever (1973) and $\mathrm{N}$-acetyl glucosamine by the modified Morgan-Elson reaction as described previously. No additional release of either reducing sugar or $\mathrm{N}$-acetyl glucosamine was observed when the residues were incubated with $10 \mathrm{mg}$ Novozyme 234 or $2 \mathrm{mg}$ Zymolyase 100T. Novozyme 234 was obtained from Novo Biolabs, Zymolyase 20T and 100T were obtained from Seikagaku Kogyo.

Chromatography of mannoproteins. Samples were dissolved in $10-50 \mathrm{ml} 10 \mathrm{~mm}$-potassium phosphate buffer, $\mathrm{pH} 6.0$ and loaded onto a $32 \times 5 \mathrm{~cm}$ column of DEAE Sephadex equilibrated with the same buffer. Unbound material was eluted with 1.61 potassium phosphate

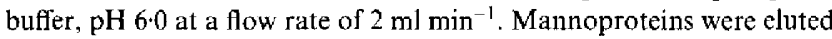
with a 2 litre linear gradient of $0-1 \mathrm{M}-\mathrm{NaCl}$ in $10 \mathrm{~mm}$-potassium phosphate buffer, $\mathrm{pH} 6 \cdot 0$. Fractions $(10 \mathrm{ml})$ were collected and assayed for carbohydrate by the phenol sulphuric assay and for protein by measurement of $A_{280}$.

Samples up to $40 \mathrm{mg}$ were dissolved in $2 \mathrm{ml} 0.5 \mathrm{M}-\mathrm{NaCl}$ and loaded onto a $102 \times 1.5 \mathrm{~cm}$ column of Sephacryl S-300 with $2 \mathrm{~cm} \times 1.5 \mathrm{~cm}$ plugs of Biogel P2 at each end. Fractions $(2 \mathrm{ml})$ were collected and assayed for protein by measurement of $A_{280}$ and for carbohydrate by the phenol sulphuric assay.

Extraction and partial purification of mannoprotein from whole cells. Washed cells from a 101 culture of $T$. cutaneum, grown for $40 \mathrm{~h}$ were suspended in $10 \mathrm{~mm}$-sodium citrate buffer $\mathrm{pH} 7.0\left[1 \mathrm{ml}\left(\mathrm{g} \text { wet } \mathrm{wt}^{-1}\right)^{-1}\right.$, and autoclaved for $40 \mathrm{~min}$ at $120^{\circ} \mathrm{C}$. The insoluble residue was collected by centrifugation, re-extracted with fresh sodium citrate buffer and centrifuged again. The combined citrate extracts were added to 5 vols $95 \%(\mathrm{v} / \mathrm{v})$ ethanol and stored at $4{ }^{\circ} \mathrm{C}$ overnight. The precipitate was redissolved in $500 \mathrm{ml}$ water and dialysed for $2 \mathrm{~h}$ against 5 I water at $4{ }^{\circ} \mathrm{C}$. Ammonium sulphate was added to $50 \%$ saturation and the solution was allowed to stand for $1.5 \mathrm{~h}$ at $4{ }^{\circ} \mathrm{C}$. The precipitate was collected by centrifugation, resuspended in $300 \mathrm{ml}$ water for $\mathrm{I} \mathrm{h}$ and centrifuged again. The supernatant was dialysed extensively against tap water to remove the ammonium sulphate and freeze-dried. The freeze-dried material $(5.31 \mathrm{~g})$ was dissolved in $100 \mathrm{ml}$ water, clarified by centrifugation and freeze-dried again.

NMR. ${ }^{13}$ C-NMR spectra were obtained with a Varian Gemini-200 NMR Spectrometer calibrated with an external standard of tertiary butanol in a coaxial capillary. Samples were dissolved in $0.6 \mathrm{ml} \mathrm{D}_{2} \mathrm{O}$. The temperature was $25^{\circ} \mathrm{C}$, the frequency was $50 \mathrm{MHz}$ and a total of 100000 transients were used. In each run the acquisition time was $1.0 \mathrm{~s}$, the delay was $1.0 \mathrm{~s}$ and the pulse width was $29 \mathrm{~ms}$. The assignment of peaks was made by comparison with spectra reported for mucoric acid (Tsuchihashi et al., 1983).

${ }^{1} \mathrm{H}$-NMR spectra were obtained from the same samples used for ${ }^{13} \mathrm{C}$ NMR spectroscopy using a Varian VXR-300 NMR spectrometer at a temperature of $75^{\circ} \mathrm{C}$ with methanol as an internal standard. The frequency was $300 \mathrm{MHz}$ and a total of 80 transients were required. In each run the acquisition time was $1.0 \mathrm{~s}$, the delay was $1.0 \mathrm{~s}$ and the pulse width was $24 \cdot 2 \mathrm{~ms}$.

\section{Results}

\section{Fractionation of the wall with alkali}

The wall preparation was fractionated with alkali to yield soluble and insoluble fractions equal to $34 \%$ and $44 \%$, respectively, (i.e. $78 \%$ of the dry wt) of the original cell walls. Possible reasons for this low recovery include limited degradation of the cell wall constituents, despite the mild extraction conditions, and losses during the ethanol precipitation of the alkali-soluble fraction. Yields of $83-84 \%$ (based on estimates of carbohydrate, protein and lipid) have been obtained from a similar fractionation of the walls of Schizosaccharomyces pombe (Manners \& Meyer, 1977) and 84-94\% from cells of Candida albicans (Sullivan et al., 1983).

\section{Chemical analysis of the whole wall and fractions}

The major constituent of the wall was neutral carbohydrate $(63 \%)$ (Table 1$)$. Other components were: protein $(11 \%)$, glucosamine $(9 \%)$ and uronic acid $(13 \%)$. The content of neutral carbohydrate is much less than is found in the walls of Saccharomyces cerevisiae (80-90\%) (Fleet, 1985) or C. albicans (80\%) (Sullivan et al., 1983), but is comparable to that in the walls of filamentous fungi, such as Schizophyllum commune (71\%) (Sietsma \& Wessels, 1977) and Trichoderma viride (30 $40 \%$ ) (Benitez et al., 1975). The amount of chitin (based on glucosamine) in the wall of $T$. cutaneum is also comparable to that found in Schizophyllum commune $(13 \%)$. The composition of the wall of $T$. cutaneum is therefore more consistent with that of a filamentous fungus than a yeast.

Hydrolysates of whole cells of $T$. beigelii contain uronic acid (Weijman, 1979) but, as far as we are aware, this is the first time that it has been described as a genuine wall component of a species of Trichosporon. The amount of glucuronic acid found in the cell wall of T. cutaneum is comparable to that in yeast cells of the Zygomycete Mucor rouxii (Bartnicki-Garcia \& Reyes, 1968).

Samples of the wall and of fractions thereof were hydrolysed and neutral sugars were assayed by GLC (Table 2). The original wall preparation contained 32\% glucose, $56 \%$ mannose and traces of xylose and galactose. The content of neutral sugars is likely to have been underestimated due to incomplete hydrolysis of polymers containing either glucosamine or uronic acid. A similar pattern of monosaccharides has been found in cell hydrolysates of $T$. beigelii (Weijman, 1979). The yields for the individual sugars detected by GLC, together with the data for protein, glucosamine and glucuronic acid, account for $91 \%$ of the cell wall preparation.

\section{Analysis of the alkali-insoluble fraction}

The alkali-insoluble fraction contained $56 \%$ neutral carbohydrate, $23 \%$ glucosamine, $7 \%$ glucuronic acid and a trace of protein (Table 1). Analysis of the neutral sugars after hydrolysis (Table 2) revealed glucose as the main component together with traces of mannose and galactose. Digestion of this fraction with Zymolyase (a lytic enzyme preparation containing a mixture of $\beta(1-3)$ 
Table 1. Percentage composition of the wall and fractions

The cell wall preparation was fractionated into alkali-soluble and -insoluble material which comprised 34 and $44 \%$, respectively, of the wall on a per weight basis. Protein, carbohydrate, glucosamine and glucuronic acid were assayed as described in Methods. Results are expressed as percentages of the total dry wt of each fraction. Figures in parentheses show the number of samples taken for each estimation. Figures for carbohydrate have been corrected for the response of glucuronic acid in the phenol sulphuric assay. Both neutral sugar and protein were destroyed under the conditions required to liberate glucosamine from chitin and did not interfere with assays of glucosamine.

\begin{tabular}{lccccc}
\hline \hline & Protein & $\begin{array}{c}\text { Neutral } \\
\text { carbohydrate }\end{array}$ & Glucosamine & $\begin{array}{c}\text { Glucuronic } \\
\text { acid }\end{array}$ & Total \\
\hline Whole wall & $11 \pm 1(3)$ & $63 \pm 1(3)$ & $9 \pm 2(6)$ & $13 \pm 0 \cdot 4(5)$ & 96 \\
Alkali-soluble & $18 \pm 0 \cdot 5(3)$ & $80 \pm 1(3)$ & $5 \pm 0 \cdot 2(6)$ & $17 \pm 1(6)$ & 120 \\
Alkali-insoluble & $4 \pm 0 \cdot 4(3)$ & $56 \pm 4(3)$ & $23 \pm 1(6)$ & $7 \pm 1(6)$ & 90 \\
\hline \hline
\end{tabular}

Table 2. Percentage of monosaccharides in hydrolysates of the wall and fractions

Samples of each fraction (5-10 mg) were hydrolysed in acid with an internal standard of $0.5-1 \mathrm{mg}$ erythritol before being converted to alditol acetates and analysed as described in Methods. All fractions contained traces of ribose and arabinose $(<0 \cdot 1 \%)$. Values are given as percentages of the dry wt of each fraction.

\begin{tabular}{lccccc}
\hline \hline Fraction & Glucose & Mannose & Xylose & Galactose & Total \\
\hline Whole wall & $32 \pm 4$ & $5 \cdot 6 \pm 0 \cdot 9$ & $0 \cdot 9$ & 2 & 41 \\
Alkali-soluble & $26 \pm 4$ & $12 \pm 2$ & 0.8 & $1 \cdot 8 \pm 0-7$ & 40 \\
Alkali-insoluble & $55 \pm 11$ & $1.8 \pm 0 \cdot 7$ & - & 3 & 60 \\
\hline \hline
\end{tabular}

glucanases; Kitamura \& Yamamoto, 1972) released reducing sugar equal to $12 \%$ of the total dry wt, indicating that the alkali-insolubie fraction contains $\beta(1$ 3 ) glucan. The remainder was resistant to hydrolysis by Zymolyase, probably due to the disposition of (1-6) branch points along the $\beta(1-3)$-linked glucan chains (see below). Novozyme 234 (a complex mixture of enzymes derived from Trichoderma harzianum, and containing glucanases and chitinase activities; Perberdy, 1979) released reducing sugar equal to at least $60 \%$ of the total dry wt.

The cell wall of a yeast or filamentous fungus may contain either chitin (a polymer of $N$-acetyl glucosamine) or chitosan (a positively charged polymer of glucosamine). In view of the high content of uronic acid in the wall, chitosan might have been expected as is seen in Mucor spp. (Datema et al., 1977). Exhaustive digestion of both the wall and the alkali-insoluble fraction with Novozyme 234 released an amount of $\mathrm{N}$-acetyl glucosamine equal to that released after hydrolysis with $6 \mathrm{M}$ $\mathrm{HCl}$ (Depree, 1992). Acetylation of these enzyme lysates (Ghosh \& Roseman, 1962) did not affect the yield of $\mathrm{N}$ acetyl glucosamine, indicating that it was derived from chitin rather than chitosan.

The alkali-insoluble fraction was sparingly soluble in
Table 3. Methylation analysis of the alkali-insoluble fraction

A sample of the alkali-insoluble wall was suspended in DMSO with sonication, and methylated according to Stoffel \& Hanflan (1973). After one cycle of methylation approximately $20 \%$ of the starting material became soluble in DMSO. The DMSO-soluble extract was methylated three times and analysed by GLC and GLC-MS as described in Methods.

\begin{tabular}{llcc}
\hline \hline $\begin{array}{l}O \text {-Methyl } \\
\text { alditol acetate derivative }\end{array}$ & Type of linkage & $\begin{array}{c}\text { Percentage } \\
\text { composition }\end{array}$ & $\begin{array}{c}\text { Molar } \\
\text { ratio }\end{array}$ \\
\hline 2,3,4,6-Tetra- $O$-methyl & Terminal hexose & $10 \cdot 0$ & $1 \cdot 5$ \\
hexitol & & & \\
2,4,6-Tri- $O$-methyl hexitol & (1-3) Glucose & $37 \cdot 6$ & $5 \cdot 8$ \\
2,4,6-Tri- $O$-methyl hexitol & (1-3) Mannose & $6 \cdot 6$ & $1 \cdot 0$ \\
2,3,4-Tri- $O$-methyl hexitol & (1-6) Hexose & $35 \cdot 3$ & $5 \cdot 5$ \\
2,4-Di- $O$-methyl hexitol & (1-3-6) Hexose & $9 \cdot 6$ & $1 \cdot 4$ \\
\hline
\end{tabular}

DMSO, but approximately $20 \%$ was rendered soluble after one cycle of methylation. This fraction yielded equivalent amounts of (1-3)- and (1-6)-linked glucose residues, with a molar ratio of 1.5 terminal residues to 1.4 (1-3-6)-linked branch points (Table 3). The glucan could be either a single $\beta(1-3) \beta(1-6)$-linked polymer of the type found in C. albicans (Gopal et al., 1984) and Schizophyllum commune (Sietsma \& Wessels, 1977), or a mixture of a predominantly $\beta(1-3)$-linked alkaliinsoluble, acid-insoluble glucan and a predominantly $\beta(1-6)$-linked acid-soluble glucan as seen in Saccharomyces cerevisiae (Fleet, 1985). The alkali-insoluble fractions contain the main structural polymers of the wall of Saccharomyces cerevisiae (Fleet, 1985) and possibly Schizophyllum commune (Sietsma et al., 1985).

\section{Analysis of the alkali-soluble fraction}

The alkali-soluble fraction contained $18 \%$ protein, $80 \%$ neutral carbohydrate, $17 \%$ glucuronic acid and a small amount $(5 \%)$ of glucosamine (Table 1). The figure of 
Table 4. Methylation analysis of the alkali-soluble fraction

A sample of the alkali-soluble wall was dissolved in dry DMSO, methylated four times (Stoffel \& Hanflan, 1973), hydrolysed and analysed using GLC and GLC MS as described in Methods. Peaks were assigned according to retention time and by comparison of the fragmentation patterns with published data (Jansson et al., 1976).

\begin{tabular}{llcc}
\hline \hline $\begin{array}{l}O \text {-Methyl } \\
\text { alditol acetate derivative }\end{array}$ & Type of linkage & $\begin{array}{c}\text { Percentage } \\
\text { composition }\end{array}$ & $\begin{array}{c}\text { Molar } \\
\text { ratio }\end{array}$ \\
\hline $\begin{array}{l}\text { 2,3,4-Tri-O-methyl } \\
\text { pentitol }\end{array}$ & Terminal xylose & $2 \cdot 4$ & 5 \\
2,3-Di- $O$-methyl pentitol & (1-4) Xylose & $0 \cdot 5$ & 1 \\
2,3,4,6-Tetra- $O$-methyl & Terminal hexose & $2 \cdot 7$ & 5 \\
hexitol & & $65 \cdot 6$ & 112 \\
2,4,6-Tri- $O$-methyl hexitol & (1-3) Glucose & $18 \cdot 4$ & 31 \\
2,4,6-Tri- $O$-methyl hexitol & $(1-3)$ Mannose & $5 \cdot 3$ & 9 \\
2,4,6-Tri- $O$-methyl hexitol & $(1-3)$ Galactose & $2 \cdot 7$ & 4 \\
2,6-Di- $O$-methyl hexitol & $(1-3-4)$ Hexose & $1 \cdot 3$ & 2 \\
4,6-Di-O-methyl hexitol & (1-2-3) Hexose & $1 \cdot 1$ & 2 \\
2,4-Di- $O$-methyl hexitol & (1-3-6) Hexose & & \\
\hline \hline
\end{tabular}

\section{Table 5. Sugar composition of the acidic mannan} fractions

Molar proportions of glucose, mannose, xylose and glucuronic acid in mannan fractions. Neutral sugars were measured by gas chromatography, glucuronic acid was measured by the carbazole assay as detailed in Methods. The proportions of mannose in each sample have been normalized to 10 . ND, Not determined.

\begin{tabular}{lcccc}
\hline \hline Fraction & Glucose & Mannose & Xylose & $\begin{array}{c}\text { Glucuronic } \\
\text { acid }\end{array}$ \\
\hline Mannan I & $2 \cdot 3$ & 10 & $1 \cdot 2$ & ND \\
Mannan II & $1 \cdot 2$ & 10 & $0 \cdot 5$ & ND \\
Mannan III & 0.9 & 10 & $2 \cdot 5$ & 3 \\
\hline \hline
\end{tabular}

$80 \%$ neutral carbohydrate is probably an overestimate due to the high colour yield of mannose in the phenol sulphuric assay (Dubois et al., 1956). Subsequent analysis by GLC (Table 2 ) showed that the neutral sugar content of the alkali-soluble fraction was $40 \%$, including glucose $(26 \%)$ and mannose $(12 \%)$. These are likely to have been underestimated because the alkali-soluble fraction contains uronic acid. Because the bond between a neutral sugar and uronic acid is resistant to acid hydrolysis, polymers containing both neutral and acidic sugars tend to hydrolyse incompletely to produce acidic oligosaccharides, which are not detected by GLC. Conversely xylose residues are easily destroyed during acid hydrolysis (Turner \& Cherniak, 1991). If each uronic acid residue were attached to a neutral sugar, then the true content of neutral carbohydrate could be as high as $57 \%$.
Methylation analysis (Table 4) showed that the alkalisoluble fraction contained $66 \%$ (1-3)-linked glucose, $18 \%$ (1-3)-linked mannose and 5\% (1-3)-linked galactose. This fraction also contained terminal xylose $(2.4 \%)$, (1-4)-linked xylose $(0.5 \%)$, terminal hexose $(2 \cdot 7 \%)$, (1-3-4)-linked hexose $(2 \cdot 7 \%),(1-2-3)$-linked hexose $(1 \cdot 3 \%)$ and (1-3-6)-linked hexose $(1-1 \%)$. The molar ratio of terminal residues to branch residues was 5:4. Despite the large proportion of (1-3)-linked glucose in this fraction it was completely resistant to Zymolyase, either because the glucan is $\alpha$-linked or because the $\beta$ linkages are protected from $\beta$-glucanases in some way. Reducing sugar equal to $18-19 \%$ of the total dry wt was released by Novozyme 234 which contains a mixture of both $\alpha$-and $\beta$-glucanases.

\section{Isolation of an acidic mannan fraction}

When the alkali-soluble fraction $(100 \mathrm{mg})$ was heated in 10 mM-potassium phosphate buffer, $\mathrm{pH} 6.0$ a small amount of material was solubilized. This material bound to DEAE Sephadex and was eluted with a linear gradient of $0-1 \mathrm{M}-\mathrm{NaCl}$ in $10 \mathrm{~mm}$-potassium phosphate buffer. Two fractions, mannan fraction I and mannan fraction II, eluted at 0.4 and $0.6 \mathrm{M}$, respectively. Both of these fractions were excluded from Sephacryl S-300 which indicates that they have $M_{\mathrm{r}}$ values of 400000 or greater. They contained glucose, mannose, and xylose in the proportions $2 \cdot 3: 10: 1 \cdot 2$, and $1 \cdot 2: 10: 0 \cdot 5$ for mannan fractions I and II, respectively (Table 5). Galactose was not detected in either fraction. The yields of these fractions $(3-6 \mathrm{mg}$ ) precluded further analysis for linkage and uronic acid content.

Mannans can be extracted by autoclaving whole cells in neutral buffer (Peat et al., 1961; Nakajima \& Ballou, 1974). This procedure produces large yields of mannan and avoids exposure to strong alkali (Okubo et al., 1981; Fleet, 1985). Whole cells of $T$. cutaneum were autoclaved in neutral citrate buffer and the mannan was precipitated as described in Methods. This fraction was applied to DEAE Sephadex and eluted with a linear gradient of $0-1 \mathrm{M}-\mathrm{NaCl}$. Elution was monitored with the phenol sulphuric assay. A broad peak was eluted at approximately $0.5 \mathrm{M}-\mathrm{NaCl}$ and a shoulder at approximately $0.4 \mathrm{M}-\mathrm{NaCl}$. The eluted material was collected as one pool (mannan fraction III) and the yield, $1.7 \mathrm{~g}$, represents $1.2 \%$ of the cell dry wt. This is comparable to the yield of mannans extracted with alkali from various Trichosporon spp. and precipitated with Fehlings solution (Gorin \& Spencer, 1968). The mannan was excluded from Sephacryl S-300 which indicates that it has an $M_{\mathrm{r}}$ of 400000 or greater; it contained only minor amounts of protein $(7.5 \%)$. The molar proportions of glucose: mannose:xylose:uronic acid were: $1: 10: 2 \cdot 5: 3$, similar 
Table 6. Methylation analysis of $T$. cutaneum mannan

A sample of the mannan was dissolved in dry DMSO, methylated four times, hydrolysed and analysed using GLC and GLC-MS as described in Methods. Peaks were assigned according to retention time and by comparison of the fragmentation patterns with published data (Jansson et al., 1976).

\begin{tabular}{llc}
\hline$=$ & \multicolumn{1}{c}{ Linkage } & $\begin{array}{c}\text { Molar } \\
\text { Percentage }\end{array}$ \\
\hline (a) Unreduced polysaccharide & & \\
2,3,4-Tri- $O$-methyl pentitol & Terminal pentose & $2 \cdot 5$ \\
2,3-Di- $O$-methyl pentitol & (1-4) Pentose & $0 \cdot 8$ \\
2,3,4,6-Tetra- $O$-methyl hexitol & Terminal hexose & $1 \cdot 1$ \\
3,4,6-Tri- $O$-methyl hexitol & (1-2) Hexose & $0 \cdot 8$ \\
2,4,6-Tri- $O$-methyl hexitol & (1-3) Hexose & 82 \\
2,6-Di- $O$-methyl hexitol & (1-3-4) Hexose & $4 \cdot 9$ \\
4,6-Di- $O$-methyl hexitol & $(1-2-3)$ Hexose & $3 \cdot 9$ \\
6-Methyl hexitol & $(1-2-3-4)$ Hexose & $0 \cdot 8$ \\
2,4-Di- $O$-methyl hexitol & $(1-3-6)$ Hexose & $1 \cdot 0$ \\
Hexa-acetyl hexitol & Unmethylated & $1 \cdot 8$ \\
(b) Carboxyl-reduced polysaccharide & & \\
2,3,4-Tri- $O$-methyl pentitol & Terminal pentose & $2 \cdot 9$ \\
2,3-Di- $O$-methyl pentitol & $(1-4)$ Pentose & $1 \cdot 6$ \\
2,3,4,6-Tetra- $O$-methyl hexitol & Terminal hexose & $14 \cdot 5$ \\
2,4,6-Tri- $O$-methyl hexitol & $(1-3)$ Glucose & $2 \cdot 6$ \\
2,4,6-Tri- $O$-methyl hexitol & $(1-3)$ Mannose & $64 \cdot 3$ \\
2,6-Di- - -methyl hexitol & $(1-3-4)$ Hexose & $3 \cdot 4$ \\
4,6-Di- $O$-methyl hexitol & $(1-2-3)$ Hexose & $11 \cdot 7$ \\
\hline , & & \\
\hline
\end{tabular}

to the two mannan fractions isolated from the alkalisoluble portion of the wall (Table 5). Galactose was not detected. Differences between fractions I, II and III may be attributed to the different methods of extraction. The proportions of xylose in these fractions have probably been underestimated due to breakdown during acid hydrolysis (Turner \& Cherniak, 1991). The uronic acid component was identified by reducing it to the corresponding neutral sugar as described in Methods. The reduced polysaccharide was then hydrolysed and analysed for glucose with glucose oxidase reagent. Both glucose and uronic acid were assayed before and after carboxyl reduction, and the increase in the amount of glucose detected after carboxyl reduction accounted for $70-85 \%$ of the uronic acid that had been consumed. Since the glucose oxidase assay is specific for D-glucose, these data show that the uronic acid in the mannan is Dglucuronic acid.

The pathogenic yeast Cryptococcus neoformans produces a mannan (Vartivarian et al., 1989) and also large amounts of a capsular polysaccharide similar in composition to the acidic mannan (Cherniak et al., 1991). These polymers do not however appear to be structural components of the wall as the only neutral sugar detected in isolated wall preparations was glucose (Vartivarian et al., 1989). Production of capsular material or extracellular polysaccharides by $T$. cutaneum has been reported (Gorin \& Spencer, 1967), but was not observed with this strain. The isolation of similar mannan fractions from both isolated cell walls and whole cells suggests that this acidic mannan is a true component of the cell wall.

\section{Linkage analysis of the T. cutaneum acidic mannan}

The structural mannoproteins of Saccharomyces cerevisiae and C. albicans (Ballou, 1982; Saxena et al., 1989) have an $\alpha(1-6)$ mannose backbone. The $\alpha(1-6)$ bonds can be specifically cleaved by acetolysis and the products separated by gel filtration to yield 'fingerprints' of manno-oligosaccharides which are specific to different species of yeast (Kocourek \& Ballou, 1969). The acidic mannan of $T$. cutaneum however was resistant to acetolysis which indicates that it lacks an $\alpha(1-6)$ mannose backbone.

Samples of mannan were methylated three times and analysed by gas chromatography and mass spectroscopy (Table $6 a$ ). The hydrolysates contained predominantly (82\%) 2,4,6-tri- $O$-methyl hexitol [(1-3)-linked], with no 2,3,5-tri- $O$-methyl hexitol [(1-6)-linked] and only traces of 2,4-di-O-methyl hexitol [(1-3-6) branch points] as expected. Xylose was present either as 2,3,4-tri- $O$-methyl pentitol (terminal residues) or as 2,3-di- $O$-methyl pentitol [(1-4)-linked chains]. Under-methylation was detected by an excess of apparent branch points over terminal residues $(11 \%: 4 \%)$ and by the presence of unmethylated hexose.

The mannan was more easily methylated following reduction of the carboxyl groups and it then showed no signs of under-methylation (Table $6 b$ ). The main component was (1-3)-linked mannose $(64 \%)$, with small amounts of terminal pentose (2.9\%) and (1-4)-linked pentose $(1 \cdot 6 \%)$. A considerable increase in both terminal hexose $(1-15 \%)$ and (1-2-3)-linked hexose (4-12\%) was observed compared with the unreduced mannan. These data are consistent with the presence of glucuronic acid as terminal residues linked directly to carbon 2 of mannose units in the (1-3) backbone. Other linkages detected were (1-2-3)-linked branch points and a small amount of (1-3)-linked glucose. No trace of 2,4-di-Omethyl hexitol or 6-methyl hexitol was found in the reduced mannan.

\section{Isolation of a polyuronic acid}

Polysaccharides consisting mainly of uronic acids can be purified from mixtures containing neutral polysaccharides by procedures that exploit their resistance to acid hydrolysis (Tsuchihashi et al., 1983). A sample $(100 \mathrm{mg})$ of the alkali-soluble fraction of the wall was hydrolysed in $10 \mathrm{ml} 0 \cdot 2 \mathrm{M}$-trifluoroacetic acid for $24 \mathrm{~h}$ at $100^{\circ} \mathrm{C}$. The supernatant was discarded and the residue 
Table $7 .{ }^{13} \mathrm{C}-N M R$ analysis of the polyglucuronan

The ${ }^{13} \mathrm{C}$-NMR spectrum of the neutral-soluble fraction, peaks were assigned based on the spectrum of a polyglucuronic acid (Tsuchihashi et al., 1983).

\begin{tabular}{ccccc}
\hline \hline Peak & p.p.m. & $\begin{array}{c}\text { Mucoric } \\
\text { acid }\end{array}$ & Difference & Assignment* \\
\hline 1 & $174 \cdot 6$ & $175 \cdot 7$ & $-1 \cdot 1$ & C6 (1-4) $\beta$-D GlcA \\
2 & $102 \cdot 6$ & $103 \cdot 4$ & $-1 \cdot 0$ & C1 (1-4) $\beta$-D GlcA \\
3 & $80 \cdot 8$ & $82 \cdot 0$ & $-1 \cdot 2$ & C4 (1-4) $\beta$-D GlcA \\
4 & $75 \cdot 3$ & $76 \cdot 6$ & $-1 \cdot 3$ & C5 (1-4) $\beta$-D GlcA \\
5 & $74 \cdot 3$ & $75 \cdot 5$ & $-1 \cdot 2$ & C3 (1-4) $\beta$-D GlcA \\
6 & $72 \cdot 9$ & $74 \cdot 0$ & $-1 \cdot 1$ & C2 (1-4) b-D GlcA \\
\hline
\end{tabular}

* GlcA. Glucuronic acid.

was made up to $10 \mathrm{ml}$ with water and neutralized with $\mathrm{NaOH}$ to yield soluble and insoluble residual fractions.

The soluble fraction was excluded from a Fractogel HW-40-S column which indicated that it has an $M_{\mathrm{r}}$ of 10000 or greater. The carbazole assay showed that it was $99 \%$ glucuronic acid.

The ${ }^{13} \mathrm{C}-\mathrm{NMR}$ spectrum of the soluble fraction was recorded and the peaks assigned based on the spectrum of a polyglucuronic acid (Tsuchihashi et al., 1983), (Table 7). The spectrum of the soluble fraction matched that of mucoric acid [poly $\beta(1-4)$-D-glucuronic acid], although peaks were consistently shifted down-field by 1.0 to 1.3 p.p.m. The ${ }^{1} \mathrm{H}-\mathrm{NMR}$ profile contained two peaks at 4.714 and 4.688 p.p.m., which were identified as belonging to the anomeric $(\mathrm{Cl})$ proton of $\mathrm{D}$-glucuronic acid; the coupling constant of these two peaks indicates that the glucuronic acid units are joined by $\beta$-linkages. These data are also consistent with a structure similar to that of mucoric acid. This fraction represents at least $2.5 \%$ of the total wall or $25 \%$ of the wall uronic acid and is therefore likely to be a significant wall component.

\section{Electron microscopy of $T$. cutaneum and $C$. albicans}

Cells of T. cutaneum and C. albicans were grown for $40 \mathrm{~h}$ and $16 \mathrm{~h}$, respectively on YPD medium, then fixed with $1.5 \% \mathrm{KMnO}_{4}$ and embedded in Epon 812 as described by Kreger-van Rij \& Veenhuis (1971) except that cells were post-stained for $1 \mathrm{~h}$ with saturated uranyl acetate in $100 \%$ ethanol prior to embedding. Sections were further post-stained for $1 \mathrm{~h}$ with saturated uranyl acetate in $50 \%$ ethanol to enhance contrast. The walls of $T$. cutaneum showed a lamellar structure characteristic of a basidiomycetous yeast (Fig. 1). In contrast, the wall of ascomycetous yeasts such as $C$. albicans showed a thick electron-lucent layer of wall surrounded by a thin electron-dense layer of mannoprotein (data not shown).
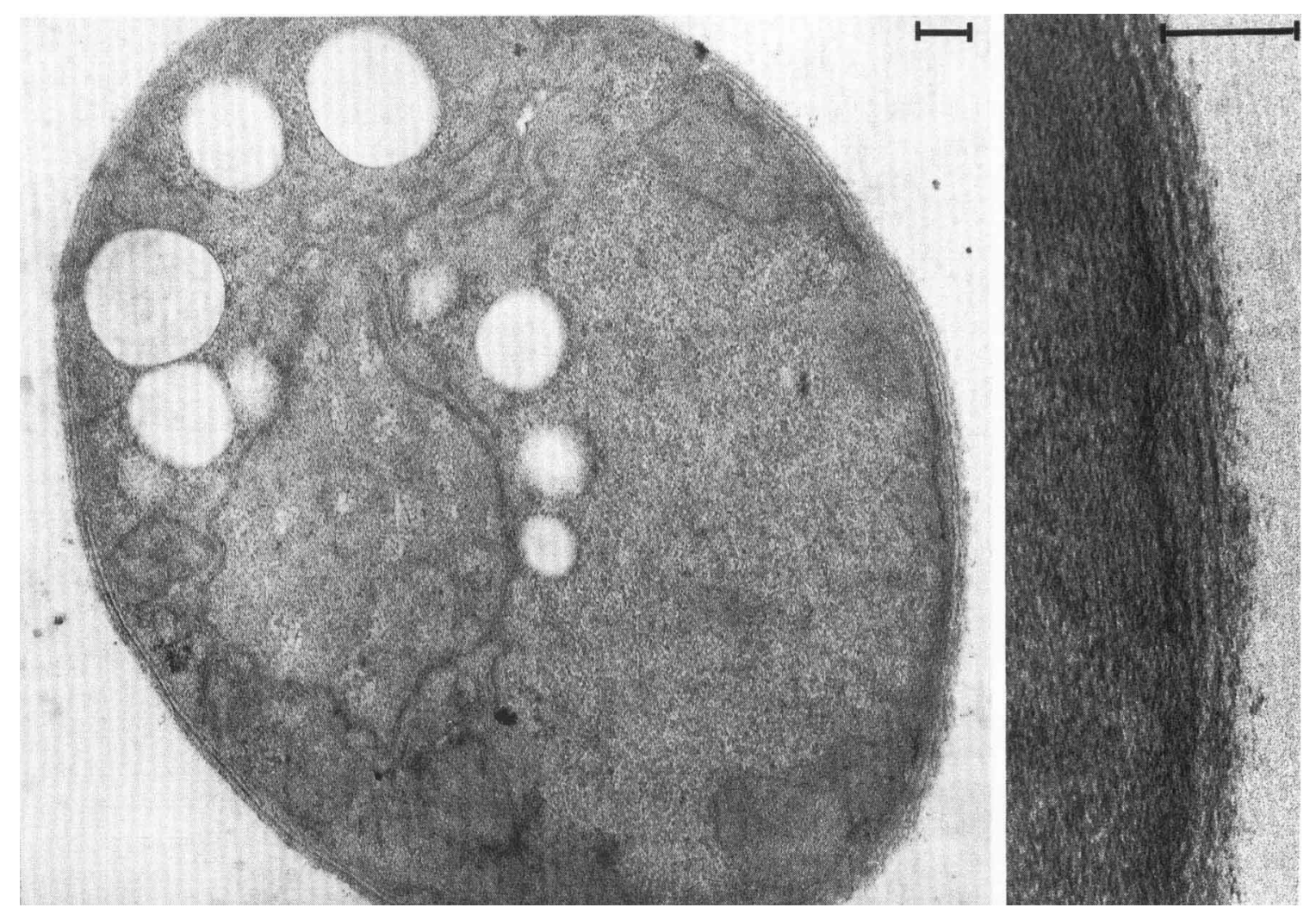

Fig. 1. A section of $T$. cutaneum prepared as described in Results. Bars, $0.2 \mu \mathrm{m}$. 


\section{Discussion}

The proportions of alkali-soluble and -insoluble material in the wall preparations of $T$. cutaneum were similar to those found in the wall of Saccharomyces cerevisiae (Fleet, 1985) but the chemical composition of the wall and fractions differed markedly. Both chitin $(9 \%)$ and neutral carbohydrate $(63 \%)$, were present in amounts more characteristic of filamentous fungi such as Schizophyllum commune (Sietsma \& Wessels, 1977) or Trichoderma viride (Benitez et al., 1975) than of a yeast. Similarly the content of mannose in the wall of $T$. cutaneum $(6 \%)$ was much lower than that found in Saccharomyces cerevisiae (25-50\%; Fleet, 1985). Uronic acid accounted for $13 \%$ of the total wall of $T$. cutaneum. Cell walls of $T$. cutaneum have not previously been assayed for glucuronic acid, but it has been found (Weijman, 1979) in cell hydrolysates of $T$. beigelii $(=T$. cutaneum). Some species of yeast, such as the pathogen Cryptococcus neoformans, produce extracellular polysaccharides containing uronic acid but these are not structural components of the wall (Vartivarian et al., 1989). As far as we are aware, the only other fungi possessing comparable amounts of uronic acid in their yeast or hyphal walls are the Zygomycetes such as Mucor spp. (Bartnicki-Garcia \& Reyes, 1968) which are not related to Trichosporon.

Hydrolysates of the alkali-insoluble fraction contained glucose, glucosamine and small amounts $(7 \%)$ of uronic acid. GLC-MS analysis of the methylated fraction showed that the glucose units were linked by a mixture of (1-3) and (1-6) bonds. The glucan in this fraction is likely to be $\beta$-linked as cells of $T$. cutaneum were lysed by either snail gut extract or by fractions of Novozyme 234 which did not contain detectable $\alpha$ glucanase activity (Depree, 1992). Exhaustive digestion of the alkali-insoluble fraction with Novozyme 234 released only $N$-acetyl glucosamine and no glucosamine, indicating that the wall contains chitin rather than chitosan. Exhaustive digestion of the alkali-insoluble fraction of $T$. cutaneum with Zymolyase released reducing sugar equal to at least $12 \%$ of the total dry wt, which indicates that this fraction contains $\beta(1-3)$ glucan. The remaining glucan is probably protected from Zymolyase by the disposition of $\beta(1-6)$ branch points along the $\beta(1-3)$-linked main chain.

The alkali-soluble fraction contained glucose, mannose, xylose, a small amount of galactose and most of the glucuronic acid. Methylation analysis revealed that $90 \%$ of the neutral carbohydrate in this fraction was (1-3)linked hexose, including $66 \%$ glucose, $18 \%$ mannose and $5 \%$ galactose. Other bond types found in the alkalisoluble fraction included (1-4)-linked xylose, (1-3-4)linked hexose, (1-2-3)-linked hexose and (1-3-6)-linked hexose. Exhaustive digestion of this fraction with Zymolyase [a preparation containing $\beta(1-3)$ glucanases; Kitamura \& Yamamoto, 1972] did not cause a measurable release of reducing sugar, whereas Novozyme 234 [which contains both $\alpha$ and $\beta(1-3)$ glucanases (Peberdy, 1979)] released reducing sugar equal to approximately $75 \%$ of the total glucose. These data suggest either that the alkali-soluble glucan is $\alpha(1-3)$-linked, or that it is protected from $\beta$-glucanases.

Two mannan fractions with $M_{\mathrm{r}}$ of 400000 or higher were isolated from a sample of the alkali-soluble fraction and purified by ion-exchange chromatography. Both fractions contained xylose but no galactose and were therefore pentosyl (xylo) mannans rather than galactomannans. This is consistent with the biochemical similarities between our isolate of $T$. cutaneum and other basidiomycetous species of Trichosporon, which have been shown to produce pentosyl mannans rather than galactomannans (Gorin \& Spencer, 1968). Neither fraction contained significant amounts of arabinose, but unlike the extracellular polysaccharide of another yeast described as T. cutaneum (Gorin \& Spencer, 1967), they contained no significant amounts of fucose, which is also a component of the galactomannan of $T$. pullulans (Gorin \& Spencer, 1968). Insufficient material precluded a determination of the uronic acid content of these fractions.

An acidic mannan isolated from whole cells was found to have a molecular mass, profile on ion exchange and content of neutral sugars similar to the two fractions isolated from the alkali-soluble portion of the wall. The acidic mannan contained glucose, mannose, xylose and glucuronic acid in the proportions $1: 10: 2 \cdot 5: 3$. The uronic acid component of this mannan was positively identified as D-glucuronic acid by carboxyl reduction and assay with glucose oxidase reagent. The acidic mannan lacks the $\alpha(1-6)$ mannose backbone found in the mannans of $C$. albicans and Saccharomyces cerevisiae (Ballou, 1982; Saxena et al., 1989), but instead appears to have an $\alpha(1-3)$-linked backbone to which single residues or short (1-4)-linked chains of xylose are attached. A comparison of the methylation patterns of the carboxyl-reduced mannan as compared to the unreduced material showed a considerable increase in both 2,3,4,6-tetra- $O$-methyl hexose (terminal residues) and 4,6-di-O-methyl hexitol [(1-2-3)-linked branch points]. The linkages of the glucose residues were not investigated, but it is noteworthy that recent studies (Van Rinsum et al., 1991) have shown that mannoprotein of Saccharomyces cerevisiae contains covalently linked glucose residues.

The presence of uronic acid moieties in a carbohydrate interferes with permethylation analysis in two ways. First, uronic acid residues are not detected by GLC-MS as used in this study. Second, any neutral sugars attached 


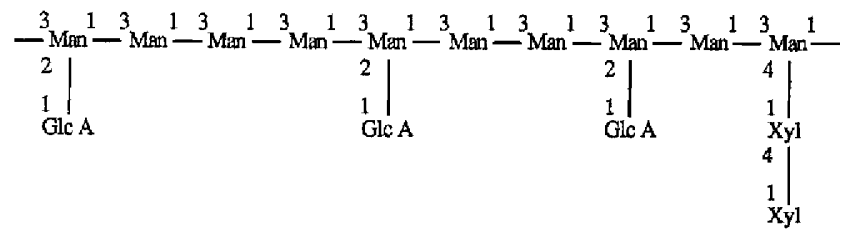

Fig. 2. Proposed structure of the carbohydrate component of the T. cutaneum acidic mannan.

to the uronic acid residues are not released by acid hydrolysis and thus are also not detected. The apparent increase in both terminal and (1-2-3)-linked branch point residues therefore is consistent with the presence of the glucuronic acid as single terminal residues linked directly to the backbone by (1-2-3) branch points. This structure (Fig. 2) is similar to the one proposed for the capsular polysaccharides of Cryptococcus neoformans, and in particular contains (1-4)-linked xylose and (1-2)-linked terminal glucuronic acid residues. These features are two of the main immunological markers for Cryptococcus neoformans capsular polysaccharide (Cherniak et al., 1980 ) and this structural similarity would be in keeping with the immuno cross-reactivity observed between the capsular antigen of Cryptococcus neoformans and a cellular antigen of $T$. beigelii (McManus et al., 1985).

A poly $\beta(1-4)$ glucuronan analogous in structure to a polymer called mucoric acid (Tsuchihashi et al., 1983) was isolated after prolonged acid hydrolysis of the alkalisoluble fraction. It consisted of chains of 50 or more glucuronic acid residues and represented $42 \%$ of the total glucuronic acid in the alkali-soluble fraction. Since this glucuronan was highly soluble in water, but could not be extracted by a simple hot-water extraction procedure, it follows that it is a component of a much larger, insoluble polymer. It is possible that the polyglucuronide is a component of an acidic glucan such as those isolated from the fruiting bodies of Polyporus fomentarus and Polyporus igniarus (Björndahl \& Lindberg, 1970).

The glucans isolated from Polyporus spp. contain an average of 4-5 $\beta(1-4)$-linked glucuronic acid residues attached to a $\beta(1-3)$-linked backbone by (1-3-6)-linked branch points (Björndahl \& Lindberg, 1970). If an acidic glucan analogous to those isolated from Polyporus were analysed by methylation and GLC-MS under the conditions specified in this study, the (1-3-6)-linked branch points would not be detected as they would remain attached to the glucuronan side chains. The methylation profile obtained would therefore appear to be of a predominantly (1-3)-linked glucan with very few (1-6)-linkages, similar to the profile obtained for the $T$. cutaneum alkali-soluble glucan. A structure of this type may also be resistant to $\beta(1-3)$ glucanases such as Zymolyase.
The chemical composition of the T. cutaneum cell wall gives some clue as to the proportions and nature of the types of polymers present. The main component of the wall is glucan $(30-40 \%)$ followed by chitin $(9 \%)$ and glucuronan $(13 \%)$. Mannan $(5 \%)$ is a minor but significant component of the wall.

Until now the biochemistry of oil production and lactose utilization by $T$. cutaneum had been studied in considerable detail but little was known of the basic biology of this yeast. We have shown that the wall of $T$. cutaneum differs markedly from that of Saccharomyces cerevisiae or C. albicans, but has some similarities with the wall of filamentous fungi. A lamellar structure characteristic of the wall of Basidiomycetes (Kreger-van Rij \& Veenhuis, 1971) has been observed in this isolate (Fig. 1). The production of an acidic xylomannan rather than a galactomannan by this organism is consistent with its classification as a basidiomycetous species of the genus Trichosporon (Gorin \& Spencer, 1968). The similarities between the acidic mannan of $T$. cutaneum and similar acidic mannans of Cryptococcus neoformans and Tremella mesenterica suggest a possible evolutionary relationship between these organisms.

As far as we are aware, this is the first time that a $\beta$ glucuronan has been isolated from a yeast not belonging to the Zygomyceteaceae. It is possible therefore that this type of polymer may be found among other genera. Preliminary data (Depree, 1992) suggests that these polyuronic acid chains play a major role in contributing to wall structure through the formation of ionic bonds.

Although $T$. cutaneum is usually referred to as an imperfect yeast, it is useful to remember that this organism also grows in a filamentous form; particularly in view of the general similarity between the walls of $T$. cutaneum and those of various filamentous fungi. The organism was first isolated from the floor drain of a dairy factory (Moon et al., 1978). It seems likely that it is found in nature as a filamentous fungus growing in soil and leaf litter, and only assumes the yeast form when grown on whey or other liquid media.

This work was supported by a grant from the Industrial Processing Division of the DSIR. We also thank Julian Davies for his advice, Raj Pannikar for assisting with the NMR, Jerry Tamate for his help with analyses of methylated carbohydrates, and K. Goldie and R. Easingwood for assisting with the electron microscopy.

\section{References}

von ARx, J. A. \& Wejuman, A. C. M. (1979). Conidiation and carbohydrate composition in some Candida and Torulopsis species. Antonie van Leewwenhoek 45, 547-555.

Ballou, C. E. (1982). Yeast cell wall and cell surface. In Molecular Biology of the Yeast Saccharomyces. Metabolism and Gene Expression, pp. 335-359. Edited by J. N. Strathern, E. W. Jones \& J. R. Broach. Cold Spring Harbour, NY: Cold Spring Harbor Laboratory.

BARNETT, J. A. (198I). The utilization of disaccharides and some other 
sugars by yeasts. Advances in Carbohydrate Chemistry and Biochemistry 39, 347-404.

Bartnicki-Garcin, S. \& Reyts, E. (1968). Polyuronides in the cell walls of Mucor rouxii. Biochimica et Biophysica Acta 170, 54-62.

Benite2, T., Villa, T. G. \& ACHA, I. G. (1975). Chemical and structural differences in mycelial and regeneration walls of Trichoderma viride. Archives of Microbiology 105, 277-282.

BrTter, T. \& Mutr, H. M. (1962). A modified uronic acid carbazole reaction. Analytical Biochemistry 4, 330-334.

Buörndahl, H. \& Lindobero, B. (1970). Polysaccharides elaborated by Polyporus fomentarus (Fr.) and Polyports igniarius (Fr.); part II, water soluble, acidic polysaccharides from the fruit bodies. Carbohydrate Research 12, 29-35.

Bt.akeney, A. B., Harrts, P. J., Henrey, R. J. \& Stone, B. A. (1983). A simple and rapid preparation of alditol acetates for monosaccharide analysis. Carbohydrate Research 113, 291-299.

Bollton, C. A. \& RatledGe, C. (1981). Correlation of lipid accumulation in yeasts with possession of ATP : citrate lyase, Journal of General Microbiology 127, 169-176.

Cherniak, R., Reiss, E., Slodki, M. E., Plattiner, R. D. \& Blumer, S. O. (1980). Structure and antigenic activity of the capsular polysaccharide of Cryptococcus neoformans serotype A. Molecular Immunology 17, 1025-1032.

Cherniak, R., Morris, L. C., Anderson, B. C. \& Meyer, S. A. (1991) Facilitated isolation, purification and analysis of glucuronoxylomannan of Cryptococcus neoformans. Infection and Immunity $\mathbf{5 9}$, 59-64.

Datema, R., Van DeN Ende, H. \& Wessels, J. G. H. (1977). The hyphal wall of Mucor mucedo. European Journal of Biochemistry $\mathbf{8 0}$, $611-619$.

Depree, J. A. (1992). The cell wall of Trichosporon cutaneum. PhD thesis, University of Otago, New Zealand.

Dubois, M., Gilles, K. A.. Hamilton, J. K., Rebers, P. A. \& Smith, F. (1956). Colorimetric method for determination of sugars and related substances. Analyical Chemistry 28, 350-356.

EGgSTEIN \& KreUTz (1967). Estimation of protein. In Techniques in Protein Chemistry, pp. 340-341. Edited by J. L. Bailey. Amsterdam, London, New York: Elsevier.

FLEET, G. H. (1985). Composition and structure of yeast cell walls. In Current Topics in Medical Mycology, pp. 24-56. Edited by M. McGinnis. New York: Springer-Verlag.

Ghosh, S. \& Roseman, S. (1962). L-Glutamine-D-fructose 6-phosphate transamidase from Escherichia coli. Methods in Enzymology 5, 414417.

Gopal, P. K., Shepherd, M. G. \& Sullivan, P. A. (1984). Analysis of wall glucans from yeast, hyphal and germ-tube forming cells of Candida albicans. Journal of General Microbiology 130, 3295-3301.

Goris, P. A. J. \& Spencer, J. F. T. (1967). A novel pentosyl mannan arising from the yeast Trichosporon cutaneum. Canadian Journal of Chemistry 45, 1543-1549.

GoriN, P. A. J. \& SPENCER, J. F. T. (1968). Galactomannans of Trichosporon fermentans and other yeasts; proton magnetic resonance and chemical studies. Canadian Journal of Chemistry 46, $2299-2304$.

GuéHo, E.. De Hoog, G. S., Smith, M. T. \& Meyer, S. A. (1987). DNA relatedness, taxonomy, and medical significance of Geotrichium capitatum. Joumal of Clinical Microbiology 25, 1191-1194.

JANSson, P. E., KenNe, L., Leidgren, H., LindBerG, B. \& LönNGRen, J. (1976). A Practical Guide to the Methylation Analysis of Carbohydrates (8). Department of Organic Chemistry, University of Stockholm.

Jeuniaux, C. (1966). Chitinases. Methods in Enzymology 8, 644-650.

Kitamlra, K. \& Yamamoto, Y. (1972). Purification and properties of an enzyme, Zymolyase, which lyses viable yeast cells. Archives of Biochemistry and Biophysics 153,403-406.

Kocourek, J. \& Ballou, C. E. (1969). Method for fingerprinting yeast cell wall mannans. Journal of Bacteriology 100, 1175-1181.

KreGer-van Ru, N. J. W. (1984). The Yeasts a Taxonomic Study. Amsterdam: Elsevier.

Kreger-van RiJ. N. J. W. \& Veenhuis, M. (1971). A comparative study of the cell wall structure of basidiomycetous and related yeasts. Journal of General Microbiology 68, 87-95.
LEvER, M. (1973). Colorimetric and fluorimetric determination with $p$ hydroxybenzoic acid hydrazide. Biochemical Medicine 7, 274-281.

LloYd, J. B. \& WhelAN, W. J. (1969). An improved method for enzymic determination of glucose in the presence of maltose. Analytical Biochemistry 30, 467-470.

Manners, D. J. \& MEyer, M. T. (1977). The molecular structures of some glucans from the cell walls of Schizosaccharomyces pombe. Carbohydrate Revearch 57, 189-203.

Matthews, R. C., Burnie, J. P., Fox, A., Woods, M. \& Tabaqchali, S. (1986). Immunoblot analysis of the serological response in invasive Trichosporon beigelii and Blastoschizomyces capitatus infections. Journal of Clinical Microbiology 23, 395-397.

McManus, E. J., Bozdech, M. J. \& Jones, J. M. (1985). Role of the latex agglutination test for cryptococcal antigen in diagnosing diseminated infections with Trichosporon beigelii. Journal of Infectious Diseases 151, 1167-1169.

Miller, R. S. \& Hoskins, L. C. (1981). Mucin degradation in human colon ecosystems. Fecal population densities of mucin-degrading bacterial estimated by a 'most probable number' method. Gastroenterology 81, 759-765.

Moon, N. J., Hammond, E. G. \& Glatz, B. A. (1978). Conversion of cheese whey and whey permeate to oil and single cell protein. Journal of Dairy Science 61, 1537-1547.

NAKAJIMA, T. \& BALloU, C. E. (1974). Characterization of the carbohydrate fragments obtained from Saccharomyces cerevisiae mannan by alkaline degradation. Journal of Biological Chemistry 249, 7679-7684.

Okubo, Y., Shibata, N., Ichikawa, T., Chaki, S. \& Suzuki, S. (1981). Immunological study on bakers' yeast mannan prepared by fractional precipitation with cetyltrimethylammonium bromide. Archives of Biochemistry and Biophysics 212, 204-215.

Peat, S., Whelan, W. J. \& EDWards, T. E. (1961). Polysaccharides of baker's yeast : part IV, mannan. Journal of the Chemical Society Part 1, 29-34.

Peberdy, J. F. (1979). Fungal protoplasts: isolation, reversion and fusion. Anmual Reviews of Microbiology 33, 21-39.

Rauvala, H. (1979). Use of triphenylmethane as an indicator of complete methylation of glycolipids and glycopeptides. Carbohydrate Research 72, 257-260.

Redgewell, R. J., Melton, L. D. \& Brasch, D. J. (1988). Cell wall polysaccharides of kiwifruit (Actinidia deliciosa): chemical features in different zones of the fruit at harvest. Carbohydrate Research $\mathbf{1 8 2}$, 241-258.

Sanford, P. A. \& ConRad, H. E. (1966). The structure of Aerobacter aerogenes A3 (S1) polysaccharide. I. A reexamination using improved procedures for methylation analysis. Biochemistry $\mathbf{5}$, 1508-1517.

SaWardeker, J. S., Sloneker, J. H. \& Jeanes, A. (1965). Quantitative determination of monosaccharides as their alditol acetates by gasliquid chromatography. Analytical Chemistry 37, 1602-1604.

Saxena, A., Hammer, C. F. \& Cinlar, R. L. (1989). Analysis of mannans of two relatively avirulent mutant strains of Candida albicans. Infection and Immunity 57, 413-419.

Sietsma, J. H. \& Wessels, J. G. H. (1977). Chemical analysis of the hyphal wall of Schizophyllum commune. Biochimica et Biophysica Acta 496, 225- 239.

Sietsma, J. H., Sonnenberg, A. M. S. \& Wessels, J. G. H. (1985). Localisation by autoradiography of synthesis of $(1-3) \beta$ and (1-6) $\beta$ linkages in a wall glucan during hyphal growth of Schizophyllum commune. Journal of General Microbiology 131, 1331-1337.

SPÁNNING, A. \& Neujahr, H. (1990). The effect of glucose on enzyme activities and phenol utilization in Trichosporon cutaneum grown in continuous culture. Journal of General Microbiology 136, 1491-1495.

StOFIEL, W. \& HANFLAN, P. (1973). Analysis of amino sugar-containing glycosphingolipids by combined gas-liquid chromatography and mass spectrometry. Hoppe-Seyler's Zeitschrift für Physiologische Chemie 354, 21-31.

Sullivan, P. A., Chiew, Y. Y., Molloy, C. Templeton, M. D. \& SHEPHERD, M. G. (1983). An analysis of the metabolism and cell wall composition of Candida albicans during germ-tube formation. Canadian Journal of Microbiology 29, 1514-1525.

TSuchiHash, H., Yadomae, T. \& MiYaZAKI, T. (1983). Structural 
analysis of the cell wall D Glucuronans from the fungi Absidia cylindrospora, Mucor mucedo, and Rhizopus nigricans. Carbohydrate Research 111, 330-335.

TURNeR, S. H. \& CheRniak, R. (1991). Glucuronoxylomannan of Cryptococcus neoformans serotype $\mathrm{B}$ : structural analysis by gasliquid chromatography-mass spectrometry and ${ }^{13} \mathrm{C}$-nuclear magnetic resonance spectroscopy. Carbohydrate Research 211, 103-116.

Van Rinsum, J., Klis, F. M. \& VAN Den ENDE, H. (1991). Cell wall glucomannoproteins of Saccharomyces cerevisiae mnn9. Yeast 7 , $717-726$.
Vartivarian, S. E., Reyes, G. H., JaCobson, E. S., James, P. G., Cherniak, R., Mumaw, V. R. \& Tingler, M. J. (1989). Localization of mannoprotein in Cryptococcus neoformans. Journal of Bacteriology $171,6850-6852$.

Weisman, A. C. M. (1979). Carbohydrate composition and taxonomy of Geotrichium, Trichosporon and allied genera. Antonie van Leeuwenhoek 45, 119-127.

West, M., Emerson, G. W. \& Sullivan, P. A. (1990). Purification and properties of two lactose hydrolases from Trichosporon cutaneum. Journal of General Microbiology 136, 1483-1490. 